\title{
Young People with Learning Disabilities and the Development of
} Sexual Relationships

\section{Rebecca Wright ${ }^{1}$}

${ }^{1}$ North Tyneside Council 


\title{
Young People with Learning Disabilities and the Development of Sexual Relationships
}

\author{
Rebecca Wright
}

\begin{abstract}
In modern society the needs of young people with learning disabilities to develop sexual relationships is increasingly recognised, and supported in legislation and social policy. The aim of this small scale, exploratory study was to understand whether young people with learning disabilities receive sex education and are given accessible information and support relating to sexualised behaviours.
\end{abstract}

The study gained professional and parental views on this topic, together with those of the young people to understand their future aspirations and the barriers they may face. The research design involved semi-structured interviews with 12 purposively selected respondents including teachers, public health nurses, young people and their parents.

Results indicated that this group of young people do receive sex education but that misunderstandings about sex and relationships are still prevalent. Professionals and parents may lack the knowledge and confidence to provide appropriate information in an accessible manner, and for professionals the emphasis is on managing inappropriate sexualised behaviours. When it comes to preparing young people for emotional relationships all those involved in the study struggled with this and the young people's aspirations differed from those of their care givers. The study concludes that support in this particular area of personal development needs to be developed.

Key words: Young People, Learning Disabilities, Sex Education, Sexual Development, Relationships.

\section{Introduction}

Historically people with learning disabilities have been discriminated against in terms of sex and relationships. Traditional misconceptions have fallen into two categories; either that people with learning disabilities exist in a perpetual childhood and are therefore not sexual, even when physically mature (Fairbairn et al 1995); or that they demonstrate inappropriate sexual urges that need to be controlled to prevent risks to self and others (Neufeld et al 2002).

Whilst such beliefs may still pervade societal attitudes towards people with learning disabilities, there has been a growth in recent years in research concerned with young people with learning disabilities developing and engaging in sexual relationships. This has been fuelled largely by changes in legislation and social policy that emphasise the human rights of disabled young people (Hall \& Hill 1996). People with developmental disabilities have the same emotional requirements for love, affection and fulfilling interpersonal relationships as does any other person (Guilio 2003). Article 8 of the Human Rights Act (1998) states that every human being has the right to respect for private and family life, and a recent Department of Health (DH) booklet states that this article is relevant to the rights of those with learning disabilities in relation to issues such as independent living and personal and sexual relationships (Department of Health 2010). The Mental Capacity Act (2005) states that a person must be assumed to have capacity to make decisions unless it is established otherwise. This supports the rights of people with learning disabilities to make independent, informed decisions in respect of relationships and sexual behaviour. 
The Education Act (1996) requires all schools to have a sex and relationship education policy and states that children with special educational needs and learning disabilities in mainstream and special schools must be properly included in sex and relationship education (Department for Education and Employment, 2000 para 1.26).

In 2001 Valuing People set out the government's commitment to improving the life chances of people with learning disabilities, emphasising their legal and civil rights to a decent education, to marry and have a family (Department of Health, 2001, para 2.2). The policy goes on to emphasise that it is important for people with learning disabilities to receive accessible sex education and information about relationships and contraception (Department of Health 2001 para 7.39).

In accordance with the shift in policy and legislation Healy et al (2009) report that most people with learning disabilities aspire to relationships, marriage and children. However, there is some evidence in the academic literature that such young people do not gain information regarding sexuality and development from their peers in the same way as their non-learning disabled contemporaries. It is suggested that this may be due to their lower levels of social skills and limited opportunities to socialise independently which impacts negatively on the formation of close emotional relationships (Garbutt 2008).

In the light of the above, the aim of this small-scale, exploratory study was to investigate if in one particular setting young people with learning disabilities are receiving support and sex education to allow them to develop relationships. The study compared professional and parental views on this topic with those of the young people in order to gain a fuller understanding of the issues from a range of perspectives. By involving young people directly in the study it was intended to raise their awareness of the importance of sex education, and inform those involved in their welfare of issues that may previously have been considered a taboo subject.

\section{Literature Review}

A review of the academic and grey literature was undertaken to source relevant material. Search terms included:

- learning/intellectual disabilities and sexuality

- learning/intellectual disabilities and sex education

- sexual behaviour and learning disabilities and

- learning disabilities and parent/carer perspectives.

A preliminary search using the Web of Knowledge allowed access to a range of data bases. This was followed up by specific searches of the reference lists of relevant papers, in particular papers in the Journal of Intellectual Disability Research. Policy documents and official publications were accessed from relevant websites including the Department of Health, Social Care Institute for Excellence (SCIE) and www.disabilitynow.org.uk. Three areas of research were identified as relevant to the aim of this study: sex education for young people with learning disabilities, societal attitudes to such young people engaging in sexual relationships, and the issues arising for services and practitioners in managing inappropriate sexualised behaviours.

\section{Sex Education and Sexual Knowledge}

In 2005 Murphy and Young reported that adolescents with disabilities seemed to be participating in sexual relationships without adequate knowledge and skills to keep them healthy and safe. This is reflected in a large scale survey of 1000 disabled people by 
Disability Now UK, almost half of whom said they had not received any form of sex education at school. The majority (84 per cent) said they were not given guidance specific to disabled people and many had been discouraged from sex altogether (Choppin 2005).

Although these studies failed to differentiate between the types of disabilities young people experienced, they are supported by findings that focus specifically on those with learning disabilities. Simpson et al (2010) audited the number of referrals for 'inappropriate sexual behaviour' to a young people's learning disability team. Results showed that in most cases children with learning disabilities received little or no sex and relationship education or support, teaching staff struggled to address the sexual health needs of these young people, the available teaching resources were outdated and staff did not have the time, commitment or confidence to deliver them.

Teaching staff in Howard-Barr et al's study (2005) reported delivering only a modest amount of sex education and rated their professional preparation for covering the topic with this group of students as inadequate. Perhaps it is therefore unsurprising that Simpson et al (2006) suggest young people with learning disabilities have a limited understanding of sex and sexual health, and Isler et al (2009) report that adolescents with learning disabilities have very low levels of correct information about sex, and the stages of adolescent development. This is supported in a three-year project running from 20072010, undertaken by CHANGE, a national organisation that fights for the rights of people with learning disabilities. Results revealed that some young people with learning disabilities harboured serious misunderstandings in relation to sexuality, for example believing that gay sex was illegal (CHANGE 2010).

However where the provision of sexual knowledge is tailored appropriately there is some evidence that young people's capacity to make decisions about their sexuality can be improved (Dukes and McGuire 2009) and some young people are receiving sex education when they are in school (Healy et al 2009). The importance of appropriate and accessible sex education for young people with learning disabilities is particularly reinforced by studies that attest to children with a learning disability being at an increased risk of sexual and physical abuse and neglect (Allington-Smith et al 2002). Disabled children may be especially vulnerable to abuse as a result of receiving intimate care, possibly from a number of carers which may increase the risk of exposure to abusive behaviour. Additionally communication difficulties may limit their ability to tell others what is happening (Department of Health, 2006, para 11.27). Accessible sex education therefore allows young people with learning disabilities to learn to protect the privacy of their own body and themselves from abuse, unplanned pregnancy, or sexually transmitted diseases (Murphy and Young 2005).

Where young people do receive such education, attention needs to be paid to effective communication between parents and professionals. Garbutt (2008) reported that many parents of young people with learning disabilities did not know what sex education their children were being taught in school and expressed concern that they had to fight for information or felt unsupported by professionals.

\section{Societal Attitudes}

Where literature has considered the views of young people with disabilities, their care givers and other interested parties regarding attitudes towards sexual relationships, there are conflicting results. Berman et al (1999) concluded that out of a sample of 29 young people the majority had hopes and desires for marriage, children and adult sex lives.

In contrast, the views of parents/carers and the wider society regarding these aspirations becoming a reality remain negative in modern culture and there is some evidence that this 
is internalised by people with intellectual disabilities and contributes negatively to their attitudes regarding their own sexuality (Cuskelly and Bryde 2004). Indeed when Evans et al (2009) asked family carers of people with learning disabilities to outline the types of relationships they thought the individual was capable of engaging in, results showed a high acceptance of platonic friendship and non-intimate relationships but intimate or marital relationships were not considered as a possibility. Some parents and teachers were prepared to go as far as supporting involuntary sterilization as a form of contraception for young people with learning disabilities (Aunos and Feldman, 2002), whilst other research suggests that parents may assume that the sexuality of their learning disabled child is irrelevant because of their level of cognitive impairment (Morris, 2001). As young people develop it has been reported that parents may also fail to encourage age appropriate expressions of sexuality such as kissing (Giulio 2003), and when adolescents begin to respond to hormonal changes and sexual feelings, parents and professionals are often frightened by the emerging behaviour (Hallum 1995).

Other research has investigated non disabled people's attitudes towards specific sex acts and behaviours. The results of a study by Milligan and Neufeld (2001) suggest sex acts involving people with disabilities are viewed more negatively than when the same behaviours are considered in the context of a non-disabled person.

Morris (2001) reported that when adolescents with learning disabilities did have boy/girlfriends they did not have the opportunity to spend time alone with them. It seems that whilst some parents display positive attitudes towards the possibility of their children having fulfilling relationships at some stage in their lives they may also keep their children under constant supervision due to concerns regarding vulnerability (Garbutt 2008). This is supported by young people in the CHANGE survey who felt they did not have enough places to go to meet others. Teachers and parents concurred with this stating that young people with learning disabilities can become very isolated (CHANGE 2010).

\section{Inappropriate Sexualised Behaviour}

The current literature also discusses the problem of inappropriate sexualised behaviour in young people with learning disabilities. Whilst some argue that masturbation is a normal behaviour through which adolescents with developmental disabilities learn about their sexual functioning (Murphy and Young 2005) a commonly reported concern is inappropriate masturbation when it occurs in public places (Hall and Hill 1996). A study undertaken by Fyson (2003) investigated the extent to which special schools were experiencing such sexually inappropriate behaviour, with results suggesting that this was a common occurrence and none of the special schools had a clear policy on how to respond. In the CHANGE study teacher and parents discussed this sensitive issue and teachers concluded that they often used techniques to redirect inappropriate masturbation such as placing a tray on a wheelchair to restrict access (CHANGE 2010).

It has been suggested that masturbation in public places by young people with learning disabilities may arise as they lack private, safe places to masturbate (Guilio 2003). As argued by Hingsburger and Tough (2002), where there is no privacy, there is no such thing as appropriate sexual expression. According to Hall and Hill (1996) young people with learning disabilities must be taught about the importance of privacy for such behaviours, a message supported by The Challenging Behaviour Foundation which offers advice on how to respond to inappropriate masturbation. An information sheet provided by The Foundation discusses difficult sexual behaviour and suggests that young men with learning disabilities can be supported to masturbate and if this behaviour occurs in school they should be directed to a private place (Thompson, undated). 
Walsh (2000) supports this view, and proposes accepting and promoting appropriate masturbation. He goes on to state that adequate access to a private place may be required to prevent masturbation occurring in front of others. Within the learning disability literature the focus on managing such sexual behaviours seems to focus on young men and the issue of young women's sexuality seems to be ignored. McCarthy (1999) points out that lesbian sexuality in women with learning disabilities is one of the least researched and understood forms of sexual expression.

In summary it transpires that whilst policy and legislative developments are in place to support sex education for young people with learning disabilities there are still a number of practical and attitudinal barriers to be overcome before changes will embed in practice. As a result this study sought to establish whether in one local authority young people with learning disabilities were being allowed and encouraged to acquire a knowledge of sexual relationships. This was explored by investigating from the perspectives of young people, parents and professionals whether:

- appropriate sex education was received in school and staff's experiences of delivering this;

- parent's views on their child's future, in terms of sexual relationships, matched the hopes and aspirations of the young people;

- staff experienced inappropriate sexualised behaviours occurring in school and how they dealt with this.

\section{Methodology}

This study was small scale in nature and designed to be exploratory in its approach in order to understand respondents' experiences in more detail. Individual semi-structured interviews were conducted with young people with learning disabilities and their parents and group interviews were conducted with professionals. This allowed some degree of triangulation of the qualitative data and comparison of the responses (Punch 2006). A qualitative design was deemed the most appropriate for the investigation as it aimed to elicit thoughts, feelings and experiences about what emerged from the literature as a sensitive topic that was rarely discussed openly (Rees 1997).

A purposive sampling strategy was employed in one local authority team for children with disabilities aged 0-18 years. Of the 155 children currently registered with the team the study sought to involve those within the age range of 11-16 as they would be in receipt of sex education in school. Young people with a learning disability were approached to participate if they had no associated physical impairment or condition on the autism spectrum. This was to establish whether some of the issues emerging from the literature applied to this specific group of young people. A total of seven young people met the criteria to participate and having received further information about the study four agreed to be interviewed along with their parents.

The sample of professionals approached to be interviewed consisted of twelve teachers and two public health nurses who worked in a special school that had close links with the local authority team. Both nurses and two of the teachers agreed to participate in the study and group interviews were conducted separately for the different disciplines. Information was provided to all participants explaining the nature of the study and seeking signed consent to their involvement. Information for the young people was produced in Communicate in Print $\left({ }^{\circ}\right.$, a system available worldwide where symbols are used to assist verbal communication. 
The interview schedules were designed with reference to the literature reviewed and anecdotal information from young people and their parents who used the local authority services. Informal feedback from staff working in the special needs school informed the topic areas covered in the group interviews. The interview schedules were piloted prior to data collection with one young person, one parent and two professionals respectively and questions were amended according to feedback. The individuals who piloted the questions were not involved in the final study.

Consequently the interview schedule for the young people focused on questions associated with what they wished for in the future in terms of having adult relationships and children, in addition to their knowledge about sex and relationships. The interview questions for parents concentrated on their views regarding their child's future in terms of developing relationships, their views on sex education, and any support they received from professionals. Interview questions for the professionals explored what sex education occurs in school and whether it was adapted to the young people's level of understanding. In addition questions were asked regarding the occurrence of sexualised behaviours and how these were dealt with in practice.

\section{Data Analysis}

All of the interviews were recorded and transcribed to allow for thematic analysis of the qualitative data (Joffe and Yardley 2004). The raw data was read and re-read to indentify themes that were then coded to indicate their belonging to a wider category (Denscombe 2007). The categories were then identified and refined by relating them to each other so that general themes could be established (Borgatti 1996).

\section{Ethical Considerations}

Ethical considerations were taken into account at each stage of the research process and ethical approval for the study was obtained from the local authority and corresponding University where the authors were based. All potential participants were given information about the study prior to data collection and all had to give consent to take part knowing that all qualitative data obtained would be anonymised. Parents had to give their consent for their children to participate before the young people were approached. In addition all participants could view the questions they were going to be asked beforehand to ensure they were comfortable with them. Parents were able to view the questions that their children would be asked before agreeing they could take part. Parents were asked to indicate if their child required assistance to read the letters they would be sent and if so letters and information sheets were provided in Communicate in Print (c). The young people were familiar with this system as it is used in school and this method ensured they could understand the information they were being given and had the opportunity to choose for themselves if they wanted to be involved.

Given the literature reviewed it was recognised that the nature of this topic had the potential to cause distress, therefore participants were informed that they were free to withdraw from the study at any time and that arrangements were in place for professional support to be available if this became necessary.

In order to respond sensitively to potential distress experienced by the young people questions were adapted to their level of understanding and they were not asked directly to discuss their knowledge of sex. A further ethical consideration of the study was the potential for responses to indicate poor parenting or professional practice that could raise concerns for the young people's welfare. Participants were therefore advised that if such 
information was disclosed the researcher would pass this information onto the relevant professionals. Participant's agreement to this was sought on the consent form.

\section{Results}

All four young people in the study confirmed that they had received sex education in school. They said they had learned 'about how to make babies' (Young person, participant 2 ) and how their body will change and develop as they get older. However as identified in the literature (Simpson et al 2006; Isler et al 2009; CHANGE 2010) there seemed to be some fundamental misunderstandings about the information they had received. In particular the consequences of the act of sexual intercourse were not fully understood.

They showed me at school that if I had sex and I go swimming my belly will get bigger (Young person participant 3)

So if you've had sex what would cause your belly to get bigger?

(Interviewer)

Just if you go swimming (Young Person participant 3)

While all the parents thought that their children should receive sex education in school they reported that they did not know the content of what was taught, although they believed it would cover everything that non-disabled children in mainstream schools would learn. Only one parent had approached the subject of sex with their child, the others being of the opinion that their children would not understand.

I haven't spoken to him about development, I couldn't explain it to him as he won't understand (Parent participant 1)

It's no good me talking to her, she won't take any notice (Parent participant 4)

The teaching staff advised that all topics taught in sex education were adapted to the young people's level of understanding, and that although topics were similar to those taught in mainstream, information is broken down and often repeated. Public health nurses reported working collaboratively with the teachers to deliver sex education and would then offer support to individual students if necessary. However both groups described how they had never had any specialised training in how to deliver sex education to young people with learning disabilities and had devised the majority of the resources they used themselves.

We have what teachers have pulled together, there's no centralised resource base or standardised resource package that all the special schools use. Resources are what we need (Teacher participant 1)

Teaching staff concurred that more resources would be beneficial to improve sex education, whilst the public health nurses stated they would benefit from being able to communicate with the young people using different methods such as Makaton.

Both professional groups were keen to stress that the young people with learning disabilities did retain information and learn from sex education lessons and that despite the lack of resources the professionals were confident in their ability to facilitate sex education. 
In terms of sexualised behaviour in school teachers advised that kissing and touching were common, often occurring between young people of the same sex:

In the toilets we might get kissing or touching occurring, this is sometimes same sex (Teacher participant 1)

As anticipated from the literature review masturbation was reported as a common occurrence. Teachers and public health nurses stated this was more common in boys, occurring only occasionally in the girls. Both groups concurred that the school's policy to respond to such behaviour was to show the young person to a private room:

If you don't let them go somewhere private and do it then they won't stop, they would just do it anyway (Public health nurse participant 2)

The professionals then provided guidance on the importance of privacy for such behaviour and it was felt that these lessons were effective.

Interestingly staff's confidence in discussing sex and behaviour did not extend to education about close personal relationships. This was an issue that all respondents in the study struggled with for a variety of reasons. All the young people said they had boy/girlfriends at the time of the interview or had in the past. One of the young people summed up their need to know more:

I would like to learn more about relationships, like having close friends, special friends that is (Young person, participant 4)

However the teacher's view was that:

Although we may teach them things in school as best we can I agree that these children don't get the opportunity to develop a relationship (Teacher participant 2)

All parents stated that their child had a boy or girlfriend at some point and all indicated they had no concerns about this and would allow them to spend time together outside of school. However this was because parents did not think their child would have any intention of engaging in a sexual relationship:

Yeah she has, she's got a boyfriend now, but by boyfriend its not like you and me think of a boyfriend............What we think of and what she thinks is very different you know, when it comes to boyfriends, she wouldn't be getting up to anything (Parent participant 4)

School staff and parents faced the dilemma of restricting relationships in school time, whilst understanding that young people with learning disabilities don't get the opportunities to develop relationships outside the school environment in the same way as non-disabled young people as they are rarely left alone:

That's very difficult. Personally I accept that they can and should happen but I don't think they should within school. It's about judging how far things should go. I'm quite happy for them to be girlfriend and boyfriend but not in school time (Teacher participant 1 ) 
I feel strongly that they don't get the opportunity to develop their relationships as other young people do. These young people are never left alone, they have no chance to explore relationships for themselves (Teacher participant 1)

Where apart from school would he meet a girlfriend, there's scarce girls at school. I would like him to have the opportunity to meet more girls. There is a lack of social outlet, the chances of meeting a girl are very scarce (Parent participant 1)

Parents and professionals agreed that young people with learning disabilities found it hard to grasp the concept of relationships and all respondents raised the issue of the young people having a number of boy/girlfriends at any one time. This appeared to be significantly different to their non-disabled contemporaries:

My boyfriend's at college, I met him through my ex, l've had 14 boyfriends altogether (Young person Participant 4)

Grasping the concept of only being with one single person at a time is hard for them. If you ask some of the girls they will list a number of boys they have decided are now their boyfriend (Teacher participant 1)

The kids always have girl and boyfriends, that's fine with us as long as there is no cause for concern (Public Health Nurse participant 2)

Despite their misgivings all the parents reported that they would like their child to have a loving relationship in their future although two said they thought this was unrealistic. All the parents stated they did not think their child would have children or that they should have the opportunity to achieve this because they would be unable to care for children of their own:

He would not have the ability to raise children, he's just a little toddler in his head (Parent participant 1)

In contrast all of the young people said they wanted a partner when they were older and three out of four said they wanted children. Interestingly the one who didn't state this was because her mother did not think she would be able to cope:

No, me mam doesn't want me to, she doesn't think I will be able to look after them (Young Person participant 2)

\section{Discussion}

The study was designed to be small scale and exploratory as it involved young people, their parents and professionals from only one local authority, therefore the findings cannot be generalised beyond this population. If the research was to be replicated it would be beneficial to interview a larger number of participants across several geographical areas so that results would be more representative of young people with learning disabilities as a whole.

The subject area was sensitive and some of the young people may have found talking about sex and relationships uncomfortable. Even though Communicate in Print (C) was used to assist communication some of the responses from the young people were inarticulate, with their answers deviating from the original question. This is a challenge for 
qualitative research that involves people with learning disabilities, as identified by Booth and Booth in 1996. This suggests that other modes of communication may need to be explored to ensure respondents have understood fully the questions they are being asked in order that their responses can be considered valid and reliable. During two of the interviews with young people in their homes their parents came back into the room whilst the interview was taking place. This may have had a negative impact on the young person's responses and suggests that there is a balance to be struck between conducting interviews in a familiar environment, whilst also giving the young people the opportunity to discuss their responses in the absence of their care givers.

Notwithstanding the limitations, the findings support Healy et al (2009) that young people with learning disabilities do receive sex education in school and that in this local authority the needs of this group are being considered with government legislation and guidance being adhered to (Department of Education and Employment, 2000). Both teachers and the public health nurses described the occurrence of sexualised behaviours as frequent, ranging from kissing and touching to public masturbation. The policy for dealing with the latter was to show the young person to a private room reflecting the guidance of the Challenging Behaviour Foundation (Thompson, undated) and Walsh (2000). The fact that staff back up this strategy with specialist sex education sessions about the importance of privacy is positive and a credit to the school. It also contradicts the findings reported by CHANGE (2010) that teachers often used techniques to curb inappropriate masturbation with no explanation.

Professionals are committed to providing information in a way that young people can understand and believe that they can learn from these lessons. However although the biological aspects of sex and development are being addressed some young people still harbour misunderstandings about the information they are given. In respect of emotional relationships staff and parents struggle to educate young people effectively even though young people say this is an area they want to learn more about.

While staff are confident in their ability to deliver sex education a lack of educative resources and training to assist them in their role is evident. This supports the findings of Simpson et al (2010). Parents also regard the delivery of sex education to be largely the domain of the education system. Whilst this may be appropriate it is clear from the study that parents and staff share similar concerns and issues. Better quality and more accessible resources could enable teachers to involve parents in the education process particularly outside school time in respect of relationship issues.

All the young people in the study had or had recently had a boy/girlfriend which supports Guilo (2003) that they have the same requirements for love and affection as non-learning disabled youngsters. On a positive note staff attitudes towards the young people engaging in relationships appeared to be liberal and accepting. That all the young people wanted a partner when they were older and the majority wanted children supports Berman et al (1999) that adolescents with disabilities have hopes and desires for marriage, children and adult sex lives. However these aspirations do not seem to be shared by the young people's parents, the majority of whom had never spoken to their child about sex and relationships and resisted the idea of their children having children of their own. These attitudes may contribute to the internalisation of negative messages about young people's sexuality as found by Cuskelly and Bryde (2004).

Further support for this is that although parents did not seem to have any concerns about their children being in a relationship, or spending time with a partner outside of school, this was primarily because they did not consider their child's relationship to be sexual in any way. This concurs with Morris (2001) who suggested parents may assume the sexuality of their learning disabled child is irrelevant because of their level of cognitive impairment. 
However figures from a borough in the West Midlands in 2005 revealed that 28 per cent of teenage mothers had some form of learning disability (Heer 2008). This suggests that parents may be misguided in their assumptions and may need more support to talk to their children about sex and relationships in more detail.

Overall the findings suggest that when relationships are accepted young people still have difficulty facilitating them. In accordance with Valuing People (DH 2001) it seems that more support needs to be available to assist young people in this regard. The provision of safe spaces where young people with learning disabilities are able to socialise with others in a supportive environment but not one where they are not under constant supervision appears to be a current gap in today's society.

Following on from the study, the children's disability team where this research took place are currently developing a programme of tools and information that can be used in the sex education of young people with learning disabilities. The results of this research suggest that such tools are needed by professionals alongside more specialist training in this particular area. In addition parents need to be supported to communicate with their children about sex and relationships and it would be beneficial if resources could be developed that children could take home from school in order to encourage educative strategies between parents and professionals, particularly with regard to personal relationships.

\section{Acknowledgements}

The authors would like to thank the young people, their care givers and the professionals who took part in this study. They would also like to thank the staff from the Children's Disability team in North Tyneside, whose knowledge, support and encouragement has been invaluable. 


\section{References}

Allington-Smith, P; Ball, R; Haytor, R., 2002. Management of Sexually Abused Children with Learning Disabilities. Advances in Psychiatric Treatment 8: 66-72.

Aunos, M; Feldman, A., 2002. Attitudes Towards Sexuality, Sterilization and Parenting Rights of Persons with Intellectual Disabilities. Journal of Applied Research in Intellectual Disabilities 15.4: 285-296.

Berman, H; Harris, D; Enright, R; Gilpin, M; Cathers, T; Bukovy, G. 1999. Sexuality and the Adolescent with a Physical Disability: Understandings and Misunderstandings. Issues in Comprehensive Paediatric Nursing 22 (4): 183-196.

Booth,T; Booth, W. 1996. Sounds of Silence: Narrative Research with Inarticulate Subjects. Disability \& Society 11: 55-69.

Borgatti, S. 1996. Introduction to Grounded Theory.

<www.analytictech.com/m6870/introtoGT.htm>

CHANGE. 2010. Talking about Sex and Relationships: The Views of Young People with learning disabilities. <http://www.changepeople.co.uk/showContent.php?id=70>

Choppin, E. 2005. Sex Talk Silenced. September Ed. Disability Now.

Cuskelly, M; Bryde, R. 2004. Attitudes Towards the Sexuality of Adults with an Intellectual Disability: Parents, Support Staff, and a Community Sample. Journal of Intellectual \& Developmental Disability 29: 255-64.

Denscombe, M. 2007. The Good Research Guide for Small Scale Social Research Projects, $3^{\text {rd }}$ Ed. Berkshire, Open University Press.

Department for Education and Employment .2000. The Sex and Relationship Guidance. Nottingham, Department for Education and Employment publications.

Department of Health. 2001. Valuing People: A new Strategy for Learning Disability for the $21^{\text {st }}$ Century. Cm. 5086. London, HMSO.

Department of Health. 2006. Working Together to Safeguard Children: A guide to interagency working to safeguard and promote the welfare of children. London, The Stationary Office.

Department of Health. 2010. The Human Rights Act and Learning Disability: Some Relevant Issues. London, The Stationary Office.

Dukes, E; McGuire, B.E. 2009. Enhancing Capacity to make Sexuality-Related Decisions in people with an Intellectual Disability. Journal of Intellectual Disability Research 53: 72734.

The Education Act. 1996. London, HMSO.

Evans, D; McGuire, B; Healy, E; Carley, S. 2009. Sexuality and Personal Relationships for People with an Intellectual Disability. Part II: Staff and Family Carer Perspectives. Journal of Intellectual Disability Research 53 (11): 913-921. 
Fairbairn, G; Rowley, D; Bowen, M. 1995. Sexuality, Learning Difficulties and Doing What's Right. London, David Fulton Publishers.

Fyson, R. 2003. Special Schools' Experiences of Sexually Inappropriate or Abusive Behaviour between Pupils. Bulletin Anne Craft Trust 45: 6-11.

Garbutt, R. 2008. Sex and Relationships for People with Learning Disabilities: a challenge for Parents and Professionals. Mental Health and Learning Disabilities Research and Practice 5 (2): 266-277.

Giulio, G. 2003. Sexuality and People Living with Physical or Developmental Disabilities: A Review of Key Issues. The Canadian Journal of Human Sexuality 12 (1): 53-68.

Hall, D; Hill, P. 1996. The Child with a Disability $2^{\text {nd }}$ Ed. Oxford, Blackwell Science Ltd.

Hallum, A. 1995. Disability and the Transition to Adulthood: Issues for the Disabled Child, the Family, and the Paediatrician. Current Problems in Paediatrics, January, 12-50.

Heer, K. 2008. Teenagers, Pregnancy, Learning Disabilities: Wolverhampton City in context. Journal of Health and Social Care Improvement, Wolverhampton University.

Healy, E; McGuire, B; Evans, D; Carley, S. 2009. Sexuality and Personal Relationships for People with an Intellectual Disability. Part I: Service-User Perspectives. Journal of Intellectual Disability Research 53 (11): 905-912.

Hingsburger, D; Tough, S. 2002. Healthy Sexuality: Attitudes, Systems, and Policies.Research \& Practice for Persons with Severe Disabilities 27(1): 8-17.

Howard- Barr, E.M; Rienzo, B.A; Rienzo, R.M; Pigg, J; James, D. 2005. Teachers Beliefs, Professional Preparation, and Practices Regarding Exceptional Students and Sexuality Education. The Journal of School Health 75: 99-104.

The Human Rights Act. 1998. London, HMSO.

Isler, A; Beytut, D; Tas, F; Conk, Z., 2009. A Study on Sexuality with the Parents of Adolescents with Intellectual Disability'. Sexuality and Disability 27 (4): 229-237.

Joffe, H. Yardley, L. 2004. Content and thematic analysis. p. 56- 68. In: Marks, D and Yardley, L (Eds). Research Methods for Clinical and Health Psychology. London, Sage Publications Ltd.

McCarthy, M. 1999. Sexuality and Women with Learning Disabilities. London, Jessica Kingsley Publishers.

The Mental Capacity Act.2005. London, HMSO.

Milligan, M; Neufeld, A. 2001. The Myth of Asexuality. Sexuality and Disability 19 (2): 91 109.

Morris, J. 2001. That Kind of Life? Social Exclusion and Young Disabled People with High Levels of Support Needs. Scope, UK.

Murphy, N; Young, P. 2005. Sexuality Children and Adolescents with Disabilities. Journal of Developmental Medicine and Child Neurology 47 (9): 640- 646. 
Neufeld, J; Klingbeil, F; Bryen, D; Silverman, B; Thomas, A. 2002. Adolescent Sexuality and Disability. Physical Medicine and Rehabilitation Clinics of North America 13: 857873.

Punch, K.F. 2006. Developing Effective Research Proposals. London, Sage Publications.

Rees, C. 1997. An Introduction to Research for Midwives .Cheshire, Midwives Press.

Simpson, S; Andrews, C; Isaac, N. 2010. Sex education for children with learning disabilities: rolling out a national resource. Nursing Times 106 (6): 16-22.

Simpson, A; Lafferty, A; McConkey, R. 2006. Out of the Shadows: A Report of the Sexual Health and Wellbeing of People with Learning Disabilities in Northern Ireland. Ulster, University of Ulster.

Thompson, D. (undated) Difficult Sexual Behaviour amongst Boys and Men with Learning Disabilities. The Challenging Behaviour Foundation.

<http://www.thecbf.org.uk/chall-behaviour/more/Difficultsexualbehaviour.htm>

Walsh, A. 2000. Improve and Care: Responding to Inappropriate Masturbation in People with Severe Intellectual Disabilities. Sexuality and Disability 18: (1). 